\title{
Antelope Bitterbrush Seedling Transplant Survival
}

\author{
Charlie D. Clements and James A. Young
}

\begin{abstract}
Antelope bitterbrush is one of the most studied western range shrubs. The browse of this species is a highly preferred and highly nutritional forage for native ungulates and domestic livestock. Antelope bitterbrush occurs from British Columbia to Montana, and south to New Mexico, and California. Using records from the U. S. Forest Service, August Hormay estimated that antelope bitterbrush occurred on over 340 million acres of rangeland in 11 states. It is found on 7.5 million acres in California alone.

Arthur W. Sampson, one of the fathers of range management, reported in 1924 that antelope bitterbrush is a strong feed that produced a solid fat on lambs. This is the first report describing antelope bitterbrush as an important browse species, and as an important shrub on winter ranges for mule deer, elk and antelope. In the late 1930s and early 1940s studies of key browse species began as it was recognized that browse species contributed to the forage base of rangelands, and were essential in the diet of mule deer. Joseph Dixon studied the food habits of California deer in different regions of the state and reported that antelope bitterbrush was very important to mule deer in northeastern California; thus the management of antelope bitterbrush was deemed critical for mule deer habitat.
\end{abstract}

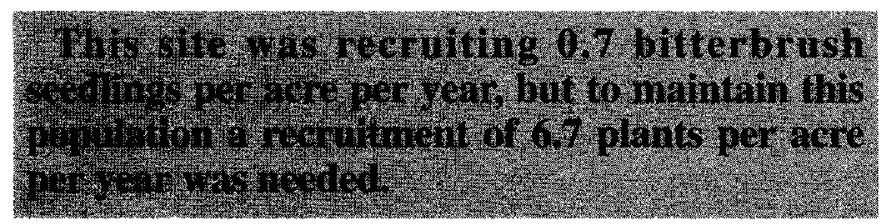

Many antelope bitterbrush ranges have been in decline because of inadequate seedling recruitment. For example, Adams (1975) reported that at a site in southern Oregon there was an average of 473 antelope bitterbrush plants per acre. This site was recruiting 0.7 bitterbrush seedlings per acre per year, but to maintain this population a recruitment of 6.7 plants per acre per year was needed. The concern over the lack of antelope bitterbrush seedling recruitment into the natural population has been an ongoing and growing concern ever since the recognition of the shrub as a key browse species.

Once it was realized that antelope bitterbrush stands were declining in vigor and density, a number of treatments were devised to enhance the communities. These treatments have included direct seeding, fertilization to increase seed production, and pruning of existing plants to increase vigor. Direct seedings of antelope bitterbrush has always been a high risk undertaking. Failure to establish stands has been attributed to poor seed quality, predation of seeds and seedlings, and competition for moisture from weeds such as cheatgrass. The problems associated with direct seeding were so chancy that it led to the transplanting of nursery grown seedlings onto rangelands. This practice grew in popularity, especially in California, because of a large pool of labor available from prison inmate crews assigned to conservation activities.

The California Department of Fish and Game (CF\&G) became very active in the collection of antelope bitterbrush seeds, nursery rearing of antelope bitterbrush seedlings, and transplanting of the seedlings to critical mule deer habitat. They were not satisfied with their seedling establishment success rate and asked our research project back in the fall of 1996 to investigate factors that contributed to successful antelope bitterbrush seedling establishment.

Field studies were located on the historic Evans Ranch located in Long Valley, Sierra County, California, about 20 miles north of Reno, Nevada. The ranch was purchased by the California Department of Fish and Game through mountain lion initiative funds. The purpose was to enhance critical habitat for wintering mule deer and inturn enhance the prey base for mountain lions. Before wildfires swept through the area in 1984 and 1985, mountain big sagebrush and antelope bitterbrush were the dominant plant species. The wildfires released herbaceous species such as Sandbergs bluegrass, western needlegrass and mules ear. Cheatgrass also invaded the area increasing the chance of wildfires and further loss of sagebrush/antelope bitterbrush communities. Because of past unsuccessful attempts at restoring antelope bitterbrush through direct seeding, the CF\&G, in cooperation with The Mule Deer Foundation, transplanted 79,000 antelope bitterbrush seedlings between 1993 and 1995. To increase establishment success, antelope bitterbrush seedlings were protected by placing a sleeve-like fine netting over the seedlings to reduce browsing by mule deer and black-tailed jackrabbits. Domestic livestock had been removed following the purchase of the land. Less than $1 \%$ seedling success was reported.

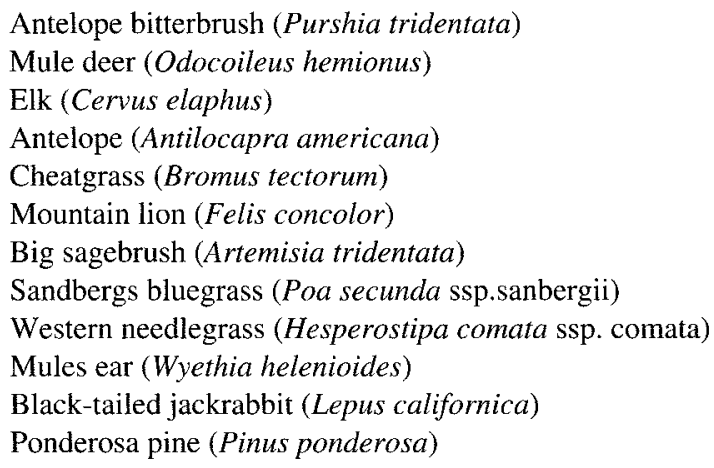

The CF \&G supplied us at the Exotic and Invasive Weeds Unit, Agricultural Research Service, USDA, with 600 of their nursery grown, bare root seedlings. These seedlings were 2-0 stock (two year old seedlings) grown in 
sterilized beds from seed collected in the general area where the transplanting was to occur. The seedlings were root pruned at 12 inches for lifting from the nursery beds. As soon as the antelope bitterbrush seedlings were examined limited chances for successful establishment of seedlings was suspected. The seedlings had made excellent top growth with shoots 14-20 inches long. Unfortunately, there were virtually no fine roots above where the tap root was cut for lifting.

When transplanting of antelope bitterbrush seedlings was first tried, it was popular to use container grown stock. Everett found through experimentation, that two-year-old stock started in the fall, held over summer in shade-houses, and transplanted very early the next spring and grown in containers of at least one quart in volume gave excellent results. These are rather expensive seedlings because of the care required and the cost of transporting the containers. Antelope bitterbrush was then grown by forest nurseries as bare root seedlings as a less expensive alternative. It is unknown if the 600 seedlings we received were a representative sample of the 79,000 planted by CF\&G.

Antelope bitterbrush seedlings were transplanted in mid April of 1996. The experimental site was located at 5,500 feet elevation on a broad northeasterly facing slope at a site that had burned 11 years before. The soils are a well drained stony sandy loam. A randomized design with four replications was used, except for the control blocks in which there were three replications, with 20 seedlings in each block. The seedlings were transplanted on three foot centers. Treatments were repeated inside and outside an existing big game exclosure, totalling 600 antelope bitterbrush seedlings transplanted. Treatments: 1) control, 2) tillage (roto-tilled with tractor mounted roto-tiller), 3) application of $0.25 \mathrm{lb} / \mathrm{ac}$ of the herbicide sethoxydim for selective grass control, and 4) inoculating the transplants with one cup of soil dug from the fine roots of established antelope bitterbrush plants growing in un-burned islands adjacent to the site. When we received the seedlings there was no evidence of root nodules. This is important because antelope bitterbrush plants are known to fix nitrogen through a symbiotic relation with a microorganism in root nodules. Transferring soil from an established antelope bitterbrush shrub is a method to inoculate the seedlings with Frankia, the microorganism that forms nodules on the roots of antelope bitterbrush plants. The numbers of surviving seedlings were recorded monthly for the next 2 years.

\section{Results}

After two years, there were significant differences in antelope bitterbrush seedling survival among treatments (Table 1). Those seedlings protected by the big game exclosure yielded better survival than those unprotected. Outside the big game exclosure no antelope bitterbrush seedlings in the control plots survived, compared to $6 \%$ survival inside the exclosure. Inoculating, tilling and herbicide spraying all increased seedling survival significantly. Mortality of transplanted antelope bitterbrush seedlings occurred largely within the first six months.

The two year old nursery reared antelope bitterbrush seedlings cost about $\$ 1.10$ each. The lower the success the more each surviving seedling ends up costing. Our initial transplant of 600 seedlings cost $\$ 1.10$ each,

labor not included. After two years, the surviving antelope bitterbrush seedlings averaged $\$ 8.15$ each. If a resource managers goal was to establish 200 antelope bitterbrush seedlings per acre, at an estimated $25 \%$ success rate, the high end of success we experienced, this would cost more than $\$ 1,000 /$ acre, labor included. The traditional method of using conservation crews, volunteers, and simply planting the seedlings in the ground, could cost as much as $\$ 7,000$ at an estimated $5 \%$ success. With many acres of bitterbrush communities in need of recruitment, the present methods of transplanting seedlings are too expensive.

The results we experienced suggest that competition with other plants, and browsing by deer and jackrabbits are inhibiting the success of transplanted antelope bitterbrush seedlings. We did not measure for soil microorganisms, but our method of inoculating the seedlings suggests that the lack of the soil microorganisms (Frankia) may also be an inhibiting factor. Our transplanting efforts took place during a wet snow storm. Both 1996 and 1997 were above average for precipitation, 18.9 inches in 1996, and 20.4 inches in 1997. The average is 14-16 inches. The quality of the bare root antelope bitterbrush seedlings when they arrive from the nursery is the crucial unknown factor in applying the results of this study. If our 600 seedling sample reflects the typical seedlings produced, successful establishment will always be limited.

Transplanting antelope bitterbrush seedlings in ponderosa pine woodlands has been more successful, but wildlife managers are more concerned with the lower sagebrush/antelope bitterbrush communities. These are the essential antelope bitterbrush communities for mule deer that are available for use during severe winters.

Table 1. Two year survival of antelope bitterbrush seedlings transplanted into control, tilled, selective herbicide treated, or soil inoculated treatments in or outside a mule deer exclosure.

\begin{tabular}{lcc}
\hline \hline Treatment & \multicolumn{2}{c}{$\begin{array}{c}\text { Surviving seedlings } \\
\text { Outside exclosure }\end{array}$} \\
\hline & Inside exclosure & Oc \\
Control & $6 \mathrm{c}$ & $15 \mathrm{~b}$ \\
Tillage & $25 \mathrm{a}$ & $8 \mathrm{ab}$ \\
Herbicide & $25 \mathrm{a}$ & $15 \mathrm{~b}$ \\
Inoculation & $27 \mathrm{a}$ & $\%$ \\
\hline
\end{tabular}

Means followed by the same letter are not significantly different at the 0.05 level of probability as determined by Duncan's Multiple Range Test. 
Further research into the condition of the root system and/or nursery practices may reveal useful information into this subject matter. Also, the question arises as to the benefits, if at all, that may occur from transplanting or direct seeding of antelope bitterbrush immediately following wildfires, before the competition with exotic weeds increases. We are not advocating that transplanting antelope bitterbrush seedlings not be considered by resource managers in their management decisions, but rather that this approach be carefully thought out. Perhaps more intense labor efforts, such as applying weed control or inoculation practices would yield more favorable results and therefore be more cost effective over time.

\section{Suggested Reading}

Adams, A. W. 1975. A brief history of juniper and shrub populations in southern Oregon. Oregon State Wildl. Comm. Wildl. Res. Rep. 6. Corvallis, Oregon. 33p.

Anon. 1937. Range Plant Handbook, USDA, Forest Service, GPO Washington, D.C.

Dixon, J. S. 1934. A study of the life history and food habits of mule deer in California. Calif. Fish and Game 20:315-354.
Everett, R. L. 1980. Use of containerized shrubs for revegetating arid road cuts. Reclamation Review 3:33-44.

Hormay, A. L. 1943. Bitterbrush in California. Res. Note 34, USDA, Forest Service, Berkeley, California.

Nord, E. C. 1965. Autecology of bitterbrush in California. Ecol. Monogr. 35:307-334.

Sampson, A. W. 1924. Native American Forage Plants. John Wiley and Sons, Inc. New York, N.Y.

Webster, S. R., C. T. Youngberg, and A. G. Wollum II. 1967. Fixation of nitrogen by bitterbrush (Purshia tridentata [Pursh] D.C.) Nature 216:392-393.

Young, V. A. and G. F. Payne. 1948. Utilization of "key" browse species in relation to proper grazing practices in cut-over white pine lands in northern Idaho. J. Forestry 46:35-40.
Authors are range scientists, USDA, Agricultural Research Service, 920 Valley Rd. Reno, Nev, 89512 E-mail charlie@scs.unr.edu

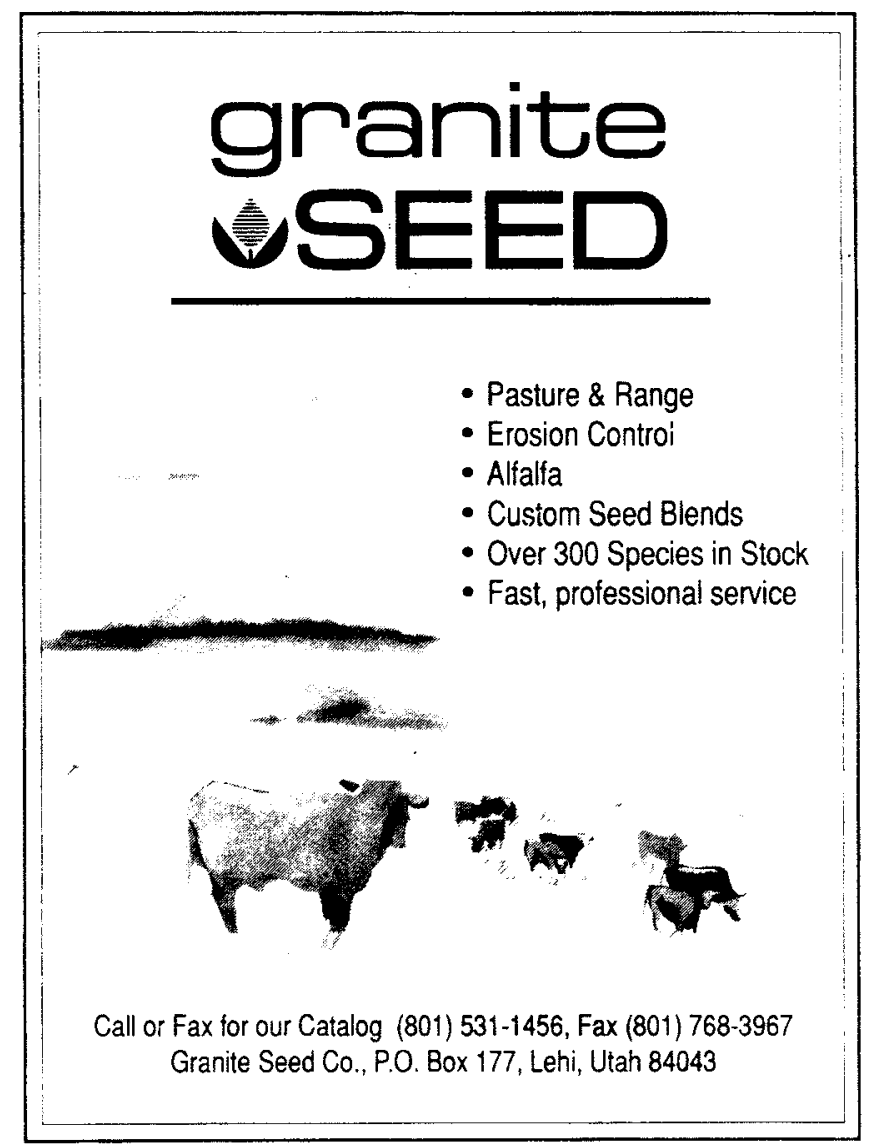

